\title{
Distal myopathy with anterior tibial onset
}

INSERM

\section{Source}

INSERM. (1999). Orphanet: an online rare disease and orphan drug data base. Distal myopathy with anterior tibial onset. ORPHA:178400

Distal myopathy with anterior tibial onset is a rare, genetic neuromuscular disease characterized by a progressive muscle weakness starting in the anterior tibial muscles, later involving lower and upper limb muscles, associated with an increased serum creatine kinase levels and absence of dysferlin on muscle biopsy. Patients become wheelchair dependent. 